\title{
Management of Petroleum Transportation Vehicles from the Perspective of Safety
}

\author{
Hongying Liu \\ Henan Police College, Zhengzhou Henan, 450002, China
}

Key words: Petroleum, Petroleum transportation vehicle, Safety monitoring.

\begin{abstract}
With continuous low-speed growth of petroleum consumption in China, safety problem caused by petroleum transportation has been increasingly prominent. Taking one of the ten major typical cases published by Traffic Management Bureau of the Ministry of Public Security - Overload Transportation of Gasoline by a Modified Vehicle for example, this paper introduces the case, organizes main legal norms and technical standards for petroleum transportation vehicles systematically and analyzes current problems of petroleum transportation vehicles such as weak safety consciousness of transportation enterprises and personnel such as drivers, failure in periodic security check of transportation vehicles and containers and incomplete road transportation safety monitoring system. A safety curtain should be jointly established by legal, administrative, economic and technical means under the policy of source control and comprehensive treatment.
\end{abstract}

\section{Introduction}

With the rapid development of Chinese automobile industry, automobile inventory has increased rapidly, causing great increase of petroleum demand. Safety problem caused by petroleum transportation has been increasingly prominent. Accidents such as petroleum leakage and explosion are common. Accidents occurring in the process of petroleum transportation have serious harms and consequences. They cause major casualties easily and might cause great secondary disasters to the society, economy and environment. Therefore, there is no time to delay safety management over petroleum transportation vehicles.

\section{Typical cases and relevant legal norms and standards}

Traffic Management Bureau of the Ministry of Public Security published 3 dangerous chemical transportation cases among 10 major typical cases of dangerous driving crime in December 2016, one of which involved overload transportation of gasoline by a modified vehicle.

Driver Mr. Tan was discovered and seized by the traffic police from Chenzhou Branch while parking a heavy tank truck for maintenance in the harbor at $434 \mathrm{~km}+500 \mathrm{~m}$ of Yueyang-Linwu Expressway (S61) in the territory of Chenzhou, Hunan Province on April 14, 2016.Upon investigation, the heavy tank truck driven by the driver Mr. Tan carried 92\# gasoline with authorized load 9500 kilograms and actual load 10955 kilograms, resulting in overload 1455 kilograms. Moreover, the vehicle was suspected of modification and assembly and forged inspection seal for July 2016 on the copy of driving license and 2016 inspection mark and compulsory insurance mark pasted on the foreside windscreen. Mr. Yao, legal representative of the company owning the vehicle, and the driver Mr. Tan were transferred to the People's Procuratorate of Jiahe County for review and prosecution according to law due to suspicion of dangerous driving crime.

Relevant laws and specifications for petroleum transportation vehicles mainly include Regulations on Safety Management over Dangerous Chemicals, Road Transportation Regulations of the People's Republic of China, Provisions on Management over Road Transportation of Dangerous Goods, Provisions on Technical Management over Road Transportation Vehicles, Method of Dynamic Supervision and Management over Road Transportation Vehicles, Provisions on Management over Road Transportation Practitioners, Regulations on Management over Road Transportation of 
Over-limit Transportation Vehicles, Marks of Vehicles for Road Transportation of Dangerous Goods, Rules on Automobile Transportation of Dangerous Goods, Specification on Vehicle Technology Management of Road Transportation Enterprises and dangerous driving crime revised in amendment (IX) of Criminal Law.These laws and regulations and technical and industrial standards jointly standardize the running security of dangerous chemical transportation vehicles and achieve the purpose of guaranteeing security management of petroleum, preventing and reducing accidents, guaranteeing life and property security of the masses and protecting the environment.

\section{Current problems of petroleum transportation vehicles}

The use of the case of overload transportation of dangerous chemical by a modified vehicle as one of the ten major typical cases published by Traffic Management Bureau of the Ministry of Public Security aims at providing same or similar judgment or treatment for same or similar dangerous chemical transportation. However, it shows from another perspective that such same or similar cases occur commonly and that the publication aims at uniform understanding. Currently, existing problems of Chinese petroleum transportation vehicles mainly include the following:

First, weak safety consciousness of transportation enterprises and personnel such as driver. Let's take overload for example. Overload makes transportation vehicles in the state of overload operation, reduces safety performance such as vehicle braking and operation and easily causes dangers such as puncture, brake failure, fracture of steel plate spring and breakage of axle shaft and great potential safety hazards. Overload transportation is not allowed for petroleum transportation. Consequences that might be caused by any danger will be unpredictable. "6.29 major accident" occurring in Guangzhou in 2012 is an instance.[1] In addition, vehicle turnover and leakage \& explosion accidents caused by human errors such as non-conformance of drivers to traffic laws in transportation and their operation against rules, fatigue driving and handling against rules are one of the main reasons for liquefied petroleum gas transportation risks. Some drivers even do not have the qualification for dangerous chemical transportation. "3.19 explosion accident of oil tank truck on Beijing-Hong Kong-Macau Expressway" occurring in 2016 sounded the alarm again.[2] These living cases fully indicate the lack of safety consciousness in current transportation of dangerous chemicals.

Second, failure in periodic security check of transportation vehicles and containers, which causes great pressure to safety transportation of petroleum. This includes problems of storage tank of tank vehicles. For example, besides conformance to relevant requirements in inspection, flaw detection and pressure-tight test, the tank shall be provided with fire safety facilities meeting safety requirements such as emergency shut-off valve, safety valve, pressure gage, liquid level meter, anti-static grounding chain and emergency fire extinguisher and be checked periodically. It also includes problems of transportation vehicles such as tire deterioration. In particular, the phenomenon of illegal modification still exists. The main reason for "1.16" major road traffic accident on Rongcheng-Wuhai Expressway in 2015 is that the supercargo of the oil tank truck violated against operating procedures of emergency shut-off valve, thus causing leakage and deflagration of gasoline, 12 persons dead, 6 persons injured and four vehicles damaged to different extents. Its direct economic loss was a bout 11 million Yuan.[3]

Third, incomplete road transportation safety monitoring system. Road law enforcement always has some weak links such as incomplete road monitoring system, road police connecting mechanism and information sharing mechanism, single law enforcement means and greater difficulty in transportation safety supervision and control in different places, thus causing inadequate law enforcement for unlicensed transportation, overload and mixed loading, bringing great difficulty to safety supervision and control and influencing regulation effect to a certain extent. Let's take "1.16" major road traffic accident on Rongcheng-Wuhai Expressway in 2015 for example. The tank of the vehicle involved in the accident was produced by a company without production qualification against rules. Quality and Technology Supervision Bureau did not perform its responsibility of compulsory product certification and regulation adequately. Road Transportation Management Office did not 
perform its responsibility of qualification authentication and supervision \& inspection for road transportation handling management of dangerous goods. The case fully reveals current problems of supervision system.

\section{Thinking on management over petroleum transportation vehicles}

With respect to management over vehicles carrying dangerous chemicals such as petroleum, we should adhere to the policy of safety and prevention first, source control and comprehensive treatment and jointly establish a safety curtain by legal, administrative, economic and technical means.

\section{Guarantee safety of petroleum transportation vehicles by legal means}

Improve relevant legal specifications. Let's take the typical case published by Traffic Management Bureau for example. The driver Mr. Tan constituted dangerous driving crime. His illegal acts include overload transportation of gasoline, gasoline transportation with a modified vehicle and forged vehicle inspection and compulsory insurance marks. His acts endangered public security. However, it is uncertain in juridical practice which illegal acts are sufficient to endanger public security. More specifically, does overload transportation of dangerous chemicals alone constitute dangerous driving crime or should overload meet a rigid standard, e.g. $30 \%$ or $50 \%$ or should overload be accompanied by illegal acts such as overspeed and fatigue driving? All these problems should be solved. The author thinks that common existence of social risks and urgent needs of the public for security require front laying of criminal defense and that dangerous driving crime with nip in the bud has been established just on this basis so as to strengthen reasonable control over social risks, prevent social harms of such behaviors from deepening and extension and improve personal sense of security. With reference to a type of dangerous driving crime - serious overload and overspeed of school buses and passenger vehicles, the standard of which for judicial conviction is $50 \%$, the constitution of dangerous driving crime for dangerous chemical transportation shall be set as overload by $30 \%$ or overload by $30 \%$ accompanied by other acts against traffic laws. Strict standards and specifications shall be adopted to standardize dangerous chemical transportation acts and guarantee the realization of safety objectives.

\section{Guarantee safety of petroleum transportation vehicles by administrative means}

Establish a joint working mechanism for law enforcement by management subjects. Dangerous chemical transportation vehicle management involves many departments such as transport, public security, safety supervision, quality supervision, sanitation, industry and commerce, environmental protection and postal service. The management over dangerous chemical transportation vehicles and practitioners is blocky. Their functions cannot complement each other and information is not shared. The effect of management is not obvious. Therefore, Regulations on Management over Road Transportation of Over-limit Transportation Vehicles specify that highway authority and road transportation management organization shall establish a joint working mechanism for law enforcement, promote networking of vehicle over-limit management information system and road transportation management information system and realize data exchange and sharing. Meanwhile, transport agency shall deliver relevant information and data to the public security organ where the vehicle is registered after handling an over-limit transportation case. The public security organ shall feed back the result of handling over-limit transportation vehicles and transportation enterprises to the transport agency. This requires public security organ of vehicle management to strengthen vehicle management files and realize information sharing for the convenience of department management.

Establish a "blacklist" of dangerous chemical transportation. Illegal transportation of dangerous chemicals has great harm. "Zero tolerance" shall be given to such behavior. Specifically, vehicles, drivers and supercargoes with over three times of illegal transportation within one year, road transportation enterprises with the number of vehicles subject to illegal transportation within one year 
exceeding $10 \%$ of the total number of its vehicles and source organizations of freight transport with over three times of illegal loading within one year shall be included in the "blacklist". Vehicle operation license and dangerous chemical transportation qualification certificate of vehicles, drivers and supercargoes included in the "blacklist" will be withheld for 6 months. Road transportation enterprises and source organizations of freight transport included in the "blacklist" shall be subject to business suspension for rectification for 3 months. Under severe circumstances, their road transportation license of dangerous goods and relevant qualification certificates shall be revoked. In the case of crime constitution, besides criminal responsibility, the same shall be prohibited from obtaining relevant qualification certificates again for a life time. Such filing system may also be linked to credit system when it is ready.

Improve access system for practitioners. Dangerous chemicals such as petroleum are strongly specialized. Some practitioners lack relevant professional knowledge and understanding of properties of chemicals and get into a panic and handle the situation improperly when encountering a problem, thus causing more serious potential safety hazards. Therefore, access threshold of practitioners shall be improved.

\section{Guarantee safety of petroleum transportation vehicles by economic means}

Implement "penalty on four subjects for one overload". In the case of illegal overload, four subjects, i.e. freight vehicle, vehicle driver, freight transport enterprise and source organization of freight transport, shall be punished. Meanwhile, such information shall be included in dangerous chemical management system so as to provide information basis for improving the "blacklist" of dangerous chemicals. Vehicles included in the blacklist shall not enjoy relevant preferential policies within one year and their compulsory insurance premium rate in the next year shall be increased. With respect to freight transport enterprises included in the blacklist, their application for over-limit transportation certificate and expansion of operating scale shall be controlled.

Implement legal responsibility strictly. Let's take overload in the typical case for example. Regulations on Safety Management over Dangerous Chemicals specify that public security organ shall instruct those involved to correct and impose a penalty of above 50,000 Yuan and below 100,000 Yuan. Road Traffic Safety Law specifies that a penalty of above 200 Yuan and below 500 Yuan shall be imposed on those exceeding the approved load and a penalty of above 500 Yuan and below 2000 Yuan on those exceeding the approved load by 30\%. Highway Security Protection Rules specify that highway authority shall instruct those involved to correct and impose a penalty of below 30,000 Yuan. According to relevant provisions above, with respect to overload, first, both public security organ and transport agency have the power of penalty; second, provisions are rough and it is difficult to master such provisions in operation. This is manifested in two aspects: first, overload is not detailed; second, penalty is not detailed either. Third, rough punishment has great differences in different provisions. The author thinks that punishment on overload transportation of dangerous chemicals such as petroleum shall be heavier than that on overload transportation of common goods and the basis for its punishment shall be Regulations on Safety Management over Dangerous Chemicals: first, Regulations on Safety Management over Dangerous Chemicals shall be detailed for practical operation - specifying a penalty of 5000 Yuan for each one ton of overload and a warning for overload less than one ton. The highest penalty shall not exceed 100,000 Yuan. Second, other provisions shall make adjustment on "handling illegal overload of dangerous chemical transportation according to relevant provisions".

\section{Guarantee safety of petroleum transportation vehicles by technical means}

Improve technical means of management. It is required to realize unification between preliminary establishment of dangerous chemical management system in each place and national dangerous chemical management system technically. This requires the improvement of vehicle file management and information sharing among different management subjects. Therefore, the system construction shall be standardized technically so as to lay a technical foundation for networking nationwide in the 
future. In addition, our dominant ideas for the management over dangerous chemicals such as petroleum shall be "strengthen source management and reduce law enforcement on road". In terms of road law executors, dangerous chemicals such as petroleum are strongly specialized. Consequences caused by improper treatment are unpredictable. Let's take the failure in periodic inspection on transportation vehicles and containers for example. Once any vehicle with overload transportation of dangerous chemicals such as petroleum is found, measures shall be taken for unloading nearby immediately. How to park and unload requires comprehensive consideration. Such vehicles may not be parked randomly. Qualified enterprises shall be selected as the base for unloading key dangerous chemicals. Nevertheless, we should also reduce law enforcement on road, realize automatic alarm and dangerous case discovery for suspected vehicles through dangerous chemical management system and vehicle GPS orientation and then enforce the law accurately for the target. Dynamic supervision and management shall be conducted for dangerous chemical transportation vehicles and the principle of enterprise monitoring, government supervision and networked joint control shall be followed.

Strengthen technical level of transportation vehicles. Encourage the development of advanced freight vehicles, focus on promoting standard vehicles such as dangerous liquid goods transportation tank truck and encourage early exit of old heavy freight vehicles from the transportation market. Strictly follow the requirement that dangerous chemical transportation vehicles shall be provided with satellite orientation devices with driving record function according to Opinions of the State Council on Strengthening Road Traffic Safety (GF (2012) No.30) and explore the installation of loading limit devices on freight vehicles and freight trains with three and more axles.

\section{Conclusion}

In conclusion, Chinese petroleum transportation vehicles have many risks in transportation currently. Relevant departments have realized its importance and hazards, strengthened management by legal, administrative, economic and technical means, set up a new name of crime - dangerous driving crime, improved legal responsibility system and jointly established a safety curtain.

\section{Acknowledgement}

This paper is a phased achievement of "Thinking on Practical Training Project of Vehicle and Driver Management" - educational reform project (24) of Henan Police College.

\section{References}

[1] China News. Notification on Deflagration Accident of Oil Tank Truck in Guangzhou by State Administration of Work Safety: Causing 20 Dead and 31 Injured.

[2] China News. Explosion Accident of Oil Tank Truck on Beijing-Hong Kong-Macau Expressway: Causing 5 Dead and 21 Injured.

[3] Shandong Administration of Work Safety. Report on Responsibility Investigation on "1.16" Major Road Traffic Accident in Laizhou, Yantai Section of Rongcheng-Wuhai Expressway [EB/OL]. 